\title{
Bruksizm teşhis ve tedavisi üzerine güncel yaklaşımlar: Derleme
}

\section{Current approaches to diagnosis and treatment of bruxism: A review}

\author{
Merve Erdoğ ÖZGÜR* Özge ARIFAĞAOĞLU@, Didem KARABEKMEZ回 \\ Başkent Üniversitesi, Diş Hekimliği Fakültesi, Protetik Diş Tedavisi Anabilim Dalı, Ankara/TÜRKIYE
}

\begin{abstract}
Öz
Bruksizm; genel kabul gören haliyle dişlerin okluzal yüzeyleri arasında non-fonksiyonel ve sürekli, kuvvetli temas olarak tanımlanır; çiğneme sisteminin non-fonksiyonel hareketleri esnasındaki istemsiz, aşırı gıcırdatma (grinding), dişlerin sıkılması (clenching), veya sürtünmesidir (rubbing). Hayatı tehdit edici bir rahatsızlık olmamasına karşın, insan yaşamının kalitesini dental problemler ve orofasiyal bölgedeki ağrı ile etkileyebilir. Günümüzde bruksizmin altında yatan nörokimyasal mekanizmalar tam olarak anlaşılamamıştır. Bununla birlikte, stres ve kişilik özellikleri gibi psikososyal faktörlerin de bruksizm etiyolojisinde önemli olduğu bildirilmiştir. Diş gıcırdatma periyodları kısa aralıklarda olmasına rağmen çiğneme sisteminde ciddi problemlere neden olabilmektedir. Bruksizm sonucu temporomandibular rahatsızlıklar, baş ağrısı, dişlerde aşınma, hassasiyet ve mobilite gibi problemler görülebilmektedir. Yıllar içinde bruksizmi durdurmak için protetik tedavilerde dahil olmak üzere birçok tedavi yöntemi denenmiştir ancak bruksizmi daimi olarak elimine eden bir tedavi yöntemi henüz bulunmamaktadır. Her ne kadar oklüzal ısırma plakları ile bruksizmin zararlı etkileri önlense de etkinliğinin net olarak gösterildiği kanıta dayalı çalışmalar bulunmamaktadır ve oklüzal tedavi bitirildiğinde uzun dönemde bruksizm tekrarlayabilir. Bu derlemede bruksizmin oluş nedenleri ve güncel tedavi yaklaşımları literatür bilgileri ışığında tartışılmıştır.
\end{abstract}

Anahtar kelimeler: Bruksizm; etyoloji; teşhis; tedavi

\begin{abstract}
The most common tooth-to-tooth habits are clenching and grinding, i.e. bruxism. Bruxism is mainly associated with rhythmic masticator muscle activity characterized by repetitive jaw muscle contractions. Although it is not a lifethreatening condition, it can affect the quality of human life with dental problems and pain in the orofacial region.The neurochemical mechanisms underlying sleep bruxism are little understood at present. Besides, it has been stated that the psychosocial factors like stress and personality is important in the aetiology of bruxism. Although intermittent clenching and grinding are extremely common, they usually pose no serious consequences for the oral structures. Sequelae of bruxism that have been proposed include tooth wear, signs and symptoms of temporomandibular disorders, headaches, toothache, mobile teeth. Currently, nospecific treatment exists that can stop sleep bruxism even though many methods, including prosthetic treatment, have been tried over the years.Currently there is no known treatment methodfor permanently eliminating bruxism. Although occlusal appliances guard against the harmful effects, they do not cure a patient ofbruxing. In most instances when long-term occlusal appliance therapy is terminated, the bruxism returns. In this review article, its etiology and current treatment methods are discussed with the light of previous literature.
\end{abstract}

Keywords: Bruxism; etiology; diagnosis; treatment

Sorumlu Yazar*: Merve Erdoğ ÖZGÜR, Başkent Üniversitesi, Diş Hekimliği Fakültesi, Protetik Diş Tedavisi Anabilim Dalı, Ankara/TÜRKiYE E-posta: merveerdog@hotmail.com

ORCID: 0000-0002-3684-5537

Gönderim: 02.02.2019 kabul: 06.02.2019

Doi: $10.18663 / \mathrm{tjcl} .521237$ 


\section{Giriş}

Parafonksiyon; çiğneme sisteminin fonksiyonel olmayan tüm hareketlerini tanımlamaktadır. Parafonksiyonel hareketlerin en sık gözleneni bruksizm olarak adlandırılan diş sıkma ve diş gıcırdatmadır. Diğer oral parafonksiyonlar yanak, dudak, dil ısırma, dil itme, tırnak yeme, kalem veya benzeri bir cismin ağızda tutulması vb. olarak sayılabilir. Parafonksiyonel aktivitelerin başlıcası bruksizmdir, bu nedenle parafonksiyonel aktivitelerle ilgili çalışmaların önemli bir kısmı bruksizm üzerinde yoğunlaşmıştır $[1,2,3,4]$.

Bruksizm, stomatognatik sistem için en zararlı olan parafonksiyonel aktivitelerden biridir [5]. Çiğneme sisteminin normal olmayan bir aktivitesi olduğu halde, bazı vakalarda hiç klinik belirti vermeyebilir $[6,7]$. Hayatı tehdit edici bir rahatsızlık olmamasına rağmen dental problemler ve orofasiyal bölgedeki ağrı ile insan yaşamının kalitesini etkileyebilir. Kraniofasiyal ağrı ve temporomandibular rahatsızlık gelişmesinde önemli rolü olduğu belirtilmektedir. Parafonksiyonel hareketler bağlamında belirttiğimiz gibi şiddetli bruksizm, normal çiğneme kuvvetlerinin süresini dakikalardan saatlere kadar arttırır, kuvvetin yönünü vertikalden çok laterale yönlendirir, normalin 4-3 katı kuvvet ortaya çıkarır ve baskı yerine makaslama kuvvetlerine neden olur [8]. Dişlerde ağrı ve ses olmaksızın ortaya çıkabildiği için hasta farkına varmadan ilerleyebilir, şiddetini artırabilir. Bu nedenle bruksizm belirtilerinin değerlendirilmesinde; hastada ağrı şikayeti olmasa bile, ağız muayenesi sırasında diş aşınmaları ve orofasial dokuların kas tonusları dikkate alınmalıdır [7].

Diş sıkma ya da gıcırdatma esnasında diş üzerine 1,5 saniyelik bir zaman diliminde $6 \mathrm{~kg}$ üzerinde bir yüklemenin olabileceği bildirilmiştir.[5] Normal fonksiyonel streslerden daha fazla olan bu yükleme; periodontal ligamentlerin harabiyetine ve alveol kemik distorsiyonlarına yol açabilir ki, dokuların tamir yeteneği bu tahribatı karşılayamaz [9]. Bruksizm birincil (idiyopatik) ve ikincil (iatrojenik) formlarda sınıflandırılmıştır. Tıbbi bir nedeni yoksa bruksizmin birincil formu gün içinde diş sıkma (clenching) ve uyku bruksizmini (UB) kapsar. Bruksizmin ikincil formları nörolojik, psikiyatrik veya uyku bozuklukları veya ilaç etkileri ile ilişkilidir [10].

\section{Bruksizmin Etyolojisi \\ Yetişkinlerde Bruksizm Etyolojisi}

Günümüzde fonksiyonel aktivitelerin periferal seviyede kontrol edilmekte olduğu, parafonksiyonel aktivitelerin ise santral sinir sistemi tarafından başlatılıp regüle edildiği belirtilmekte ve bruksizmin santral sinir sitemi merkezli olduğu düşünülmektedir [1]. Bruksizmin etiyolojisinde dental, sistemik ve psikolojik faktörlerin rol oynadığı belirlenmiş olmakla beraber bu faktörlerin hangisinin baskın olduğu halen tartışma konusudur [8]. Multifaktöriyel olduğu iddia edilmektedir [9].

Etyolojisine göre sınıflandırma yapıldığında;

- Primer, esansiyel veya idiopatik bruksizm: görünür bir nedene dayanmayan

-Sekonder bruksizm: hastalıklara sekonder olarak ortaya çıkan (koma, icterus, serebral palsi), tıbbı ürünler (antipiskotik, kardiyoaktif ilaçlar), uyuşturucu maddeler (amfetamin, ekstazi, kokain) [11]

Başlangıçta, malokluzyon ve okluzal çatışmalar gibi periferal (morfolojik) faktörler sorumlu tutulmuştur. Ancak çalışmalarda uyku bruksizminin okluzal çatışmaları olan ve olmayan hastalarda prevalansının yakın olduğu saptanmıştır. Aynı zamanda okluzyonun tedavisiyle de prevalans azaltılamamıştır. Aynı zamanada uyku bruksizmin anatomik-yapısal faktörlerle arasında bir korelasyon tespit edilememiştir.

Bruksizmin Klinik Formları

Günümüzde kabul edilen sınıflamaya göre ise iki tip bruksizm olduğu belirtilmektedir.

1.Gün içinde meydana gelen bruksizm (Diurnal)

2.Uykuda meydana gelen bruksizm(Nokturnal)

\section{Diurnal Bruksizm}

Uyanıklık durumunda ortaya çıkan bruksizm, istemsiz kas kasılması ile karakterize olup, diş sıkma ön plandadır; diş gıcırdatma daha seyrektir [6]. Genellikle birey diurnal bruksizminin farkında değildir [1]. Bu aktivite stesli bireylerde daha sıkgözlenir. Çoğunlukla uykusuzluk, gerginlikveanksiyete durumlarında meydana gelir ve toplumun yaklaşık \%6 sında görülür [6]. Kadınlarda erkeklere göre daha sık rastlanır ve ilerleyen yaşla beraber görülme sıklığı azalır [11]. Zaman zaman asemptomatik bireylerde de diş sıkmanın görülebildiği belirtilmektedir. Gün içinde gerçekleşen parafonksiyonel aktiviteler; diş sıkma, diş gıcırdatma, parmak ve dil emme, çene ve dil itme, anormal duruş, kalem ısırma, tırnak yeme, telefon veya keman gibi nesneleri çenesinde tutma gibi kişinin günlük hayatta farkında olduğu alışkanlıklardır. Bu tip aktiviteler gün içinde bireyler işlerine konsantre olduğunda ya da yoğun fiziksel kuvvet sarf ederlerken görülür [12].

\section{Nokturnal Bruksizm}

Nokturnal bruksizm uyku sırasında çene kaslarında kasılma 
ile oluşan yineleyici ve ritmik aktivitedir. Genç yaşta daha sıktır, yaş ilerledikçe azalır..Erişkin nüfusun yaklaşık \%4'inde görülür. Altmış yaşın üstündeki bireylerde ise \%2 oranında görülmektedir. Cinsiyet farkı göstermez. Diş sıkma ve gıcırdatmanın farklı etyolojileri olup olmadığı veya aynı olayın farklı şekilde ortaya çıkıp çıkmadığı bilinmemektedir. Birçok hastada bu iki aktivite birlikte meydana gelir ve birbirinden güçlükle ayırt edilirler [10]. Günümüzde nokturnal bruksizmin hastanın emosyonel durumuyla ilişkili bir uyku bozukluğu olduğu kabul edilmektedir [6]. Geceden geceye değişen derecelerde meydana geldiği ve hastanın gün içinde yaşadığı veya ilerleyen günlerde yaşayacağı olayların meydana getirdiği strese bağlı olduğu belirtilmektedir [7]. Ayrıca düzensiz çalışma saatlerinin uyku bozuklukları ve yorgunluğa neden olan faktörler içerisinde olduğu belirtilmiştir.

Uyku bruksizmi ve duygusal stres gibi psikososyal faktörler arasında ki bağlantı, uyku bruksizmli hastaların idrarında artmış ketakolamin düzeyiyle tespit edilmiştir. Illave olarak uyku bruksizm aktivitesi, yüksek algılanan psikolojik stres ve tükürük kortizol düzeyleri ilişkili bulunmuştur. $[6,10]$

Kontrollü bir laboratuvar çalışmasında uyku bruksizmli hastalarının daha rekabetçi oldukları ve normal deneklerden daha fazla endişe duydukları bildirilmiştir.

Hem uyanık bruksizim hem de uyku bruksizm hastaları bruksizmi olmayan hastalarla karşılaştırıldığında; anksiyete, depresyon, düşmanlık, fobik anksiyete ve paronoid düşünme anlamlı derecede farklılık göstermiştir [11].

\section{Bruksizm Teşhisi}

Klinisyenlerin bruksizmi tedavi etmek için öncelikle teşhis etmeleri gerekir. Basit bir ilk taramayla hastanın dişlerini gıcırdatması veya sıkması sorgulanmalıdır [13]. Klinisyenin incelemeye değer bulduğu durumlarda anamnez derinleştirilmelidir. Bruksizm ile normal fonksiyon farklı açılardan değerlendirilebilir.

\section{Uygulanan Kuvvetin Yönü}

Çiğneme ve yutma sırasında mandibula vertikal yönde hareket eder. Çene kapandığında ve diş kontakları oluştuğunda baskın kuvvetler vertikal yönde kabul edilebilir boyutlarda olur. Bruksizmde ise mandibula sağa sola kaydırma hareketi yaptığında güçlü horizontal kuvvetler oluşur. Bu kuvvetler dişler ve destekleyici yapılarda yıkıcı kuvvetler meydana getirir[14].

\section{Mandibula Pozisyonu}

Çoğu fonksiyonel aktivite sentrik okluzyonda veya sentrik okluzyona yakın oluşur. Fonksiyonel aktivitelerle ilişkili kuvvetler birçok diş üzerinde dağılarak tek diş üzerindeki potansiyel hasarı minimalize eder. Bruksizmde eksentrik pozisyonlar oluşur. Mandibulanın stabil pozisyonundan uzak olan bu aktivitede yalnızca birkaç diş teması oluşur. Bu pozisyon, çiğneme sisteminde daha çok gerilme yaratır ve sistem yıkıma daha duyarlı hale gelir [14,15].

\section{Kas Kontraksiyon Tipi:}

Çoğu fonksiyonel aktivite eklemin kontrol edilebilir ritmik kasılmasını ve rahatlamasını sağlar. Bu ritmik kasılmalar yeterli kan akımına olanak tanır. Böylece dokulara oksijen taşınır ve hücresel düzeyde akümülasyon olur. Bruksizmde kasılmalar uzun periyodlar şeklindedir. Bunun sonucu olarak hücrelerin karbondioksit ve hücresel atık düzeyi artar. Bu durum ise kasın yorulmasına, ağrı ve spazmlara neden olur.

\section{Koruyucu Reflekslerin Etkisi:}

Nöromuskuler refleksler fonksiyonel aktivite boyunca diş yapılarını hasardan korumayı hedefler. Bruksizmde nöromuskuler koruma mekanizmalarının olmadığı veya en azından refleks eşiklerinin kas aktivitesi üzerinde daha az etki ile sonuçlandığı anlaşılmaktadır. Bu yüzden, aynı diş kontakları fonksiyonel aktivitedeyken kas aktivitelerini inhibe ederken; parafonksiyonel aktivitede inhibe etmez [13].

Pintado ve ark. anket sorularının 2 tanesine pozitif cevap veren bireylerin, bruksizmi olan bireyler olarak sınıflanabileceğini belirtmişlerdir [30]. Ancak bu yöntem bruksizmin teşhisinde klinik değerlendirme veya diğer objektif değerlendirmeler kadar doğru bilgiler vermemektedir. Çünkü bruksizm epizotlarının \% 80' inde ses duyulmamaktadır. Ayrıca yetişkin ve çocukların büyük bir bölümü bruksizm alışkanlıklarının olduğunun farkında değildirler. Epidemiyolojik çalışmalarda da farklılıklar gözlenmesinin esas sebebi anket yöntemi kullanılması ve bireylerin kendi raporları doğrultusunda sonuca varılmasıdır. Bu nedenle çeşitli toplumlardaki bruksizm prevalansı tam olarak bilinmemektedir.

\section{Bruksizmin değerlendirilmesi için kullanılan anket soruları}

1 Daha önce birisi size geceleri dişlerinizi gıcırdattığınızı söyledi mi?

2 Daha önce sabah uyandığınızda çenenizde yorgunluk hissi oldu mu?

3 Sabah uyandığınızda dişlerinizde ve dişetlerinizde acıma hissi oluyor mu?

4 Daha önce sabah uyandığınızda baş ağrınız oldu mu? 
5 Daha önce gün içinde dişlerinizi gıcırdattığınızı fark ettiniz mi? 6 Daha önce gün içinde dişlerinizi sıktığınızı fark ettiniz mi? Klinik bulgular; diş aşınması, dişlerde mobilize artışı, pulpitis, çiğneme kaslarında artmış tonu, abfraksiyon, restorasyonların veya dişlerin kırılması, duyulabilir diş gıcırdatma olarak özetlenebilir.

Diş aşınması ; bruksizmin en belirgin bulgusudur, normal çiğneme sebebiyle oluşmayan okluzal veya insizal incelmedir [11]. Günümüzde aşınmaların büyük bir kısmı parafonksiyonel hareketlerden meydana gelmektedir $[1,2,10]$.

Dişlerde mobilite artışı ; periodontal açıdan sağlıklı dişlerde görülen mobilite bruksizmin bir belirtisi olarak kabul edilir. Radyografik olarak periodontal membran boşluğunda kalınlaşma olur. Nokturnal bruksizmli hastaların dişlerinde mobilitenin, sabah saatlerinde günün ilerleyen saatlerine göre daha fazla olduğu belirtilmiştir. Özellikle sabah saatlerinde hastalar bu dişleri ile ısırdığında ağıı duyduklarını belirtmektedirler [11].

Pulpitis ; parafonksiyonel aktivite kaynaklı okluzal kuvvetler, özellikle birkaç diş üzerine yoğunlaştığı zaman, apikal foramenden kan akımını etkileyerek pulpitise neden olabilirler. Daha çok reversibl pulpitis semptomları görülür [2]. Soğuğa karşı meydana gelen pulpal hiperemi bruksizmin işareti olabilir [11]. Eğer bu kuvvetler kan akımını durduracak olursa pulpa nekrozu gerçekleşir.

Çiğneme kaslarında artmış tonus, hipertrofi ve ağrı ; çiğneme kasları, bruksizmli hastalarda palpasyona karşı hassas olurlar. Hassas bölgeler masseter kası, medial pterygoid kas, bazen de temporal kas bölgesi olabilir. Nokturnal bruksizm görülen bireylerin \%65'inde temporal bölgede baş ağrısı şikayeti bulunurve başağrısışikayeti olan bireylerin, olmayanlara oranla üç kat fazla bruksizm anamnezi verdiklerini bildirmişlerdir. [11] Abfraksiyon; stres yoğunlaşması olan bölgelerde dişmaddesinde meydana gelen mikroyapısal kayıptır. Genelde dişin servikal bölgesinde meydana gelir. Bu bölgede mine oldukça incedir ve dişteki esneme ile kırılabilir, sement ve dentinde mikrofraktürler oluşabilir. Abfraksiyonlar yarım ay şeklinde olup çoğunlukla maksiler ve mandibular birinci premolar ve onu takiben ikinci premolar ve kanin dişinin bukkal yüzünde görülür [2].

Restorasyonların veya dişlerin kırılması; fraktürler, sağlam dişte meydana gelebileceği gibi, sıklıkla restorasyonlu dişlerin tüberkül tepelerinde meydana gelir. Tüberkül eğimlerine gelen horizontal kuvvetler diş kırımalarının başlıca nedenidir. Ayrıca kron veköprülerin tekrarlayan desimantasyonu da bruksizmin belirtisi olabilir [13].

Duyulabilir diş gıcırdatma ; diş gıcırdatma sırasında meydana gelen seslerin hasta veya bir yakını tarafından belirtilmesi, teşhis konulmasını sağlar [14]
Diğer belirtiler; çenede yorgunluk ve dişlerde yer değişiklikleri nokturnal bruksizmi düşündürmelidir . Yumuşak dokuda gözlenebilecek belirtiler, yanak ısırmaya bağlı olarak görülen linea alba, yaprak dil ve bukkal ağız mukozası üzerinde diş çentikleridir. Ekzostos ve toruslar, bruksizm alışkanlığı olan bireylerde, olmayanlara göre daha sık görülmektedir. Bu kemik büyümeleri, cerrahi olarak çıkarılsa bile bruksizm devam ederse yeniden oluşabilirler [11]. Çene açılımında deviasyon ve sınırlı ağız açılması bruksizmin diğer belirtileri olabilir [13].

\section{Bruksizmde Tedavi Seçenekleri}

Çiğneme sisteminin disfonksiyonundan etkilenen bölgeler kaslar, temporomandibular eklem (TME) ve dişler olarak sıralanabilir. Kas ve TME kaynaklı bozukluklar temporomandibular rahatsızlıklar olarak ifade edilmektedir [1]. Günümüze kadar temporomandibular rahatsızlıkları ifade etmekte birçok terim kullanılmıştır. 1124'de James Costen TME ve kulak çevresinden kaynaklanan bir grup semptom tanımlamıştır. Özellikle arka dişlerin kaybedilmesinin kulak içi basıncı attırdığı, bunun da semptomlara yol açtığı düşünülmüştür ve bu sendrom Costen Sendromu olarak anılmıştır. Ramfjord ve Ash ise fonksiyonel temporomandibular eklem bozuklukları terimini önermiştir. Daha sonra "Temporomandibular Rahatsızlıklar" (TMR) terimi benimsenmiştir. Bu terim sadece TME ve çiğneme kaslarından kaynaklanan problemleri içermekle kalmaz, aynı zamanda çiğneme sistemi fonksiyonu ile ilgili bozuklukların tümünü kapsar. Amerikan Orofasiyal Ağrı Akademisi ve Amerikan Diş Hekimliği Birliği de bu terimi benimsemiştir.

J.P. Okeson, TMR'yi 4 ana gruba ayırmıştır: [14]

1. Çiğneme kası rahatsızlıkları

1. Temporomandibular eklem rahatsızlıkları

2. Kronik mandibular hipomobilite

4. Gelişimsel rahatsızlıklar

TMR'nin tedavisi hastadan hastaya göre farklılık gösterir, bazı olgularda farklı disiplinlerin de müdahale etmesi gerekebilir. TMR'nin etyolojisi multifaktöriyeldir ve tedavisi multidisipliner bir yaklaşım gerektirir. Tedavi geri dönülebilir (koruyucu) olmalıdır. Koruyucu tedaviler mümkün olduğunca basittir, çünkü çoğunlukla yıkıma neden olan bir durum söz konusu değildir ve gerekli rutin kontroller yapıldığında çenelerin veya dişlerin yapısında veya pozisyonunda kalıcı değişikliklere neden olmazlar. TMR'nin tedavisinde bilgilendirme ve kendi kendini koruma programından, cerrahi operasyonlara kadar birçok tedavi programı vardır: 
1.Geri Dönüşümlü (Koruyucu) Tedavi:

1.1. Bilgilendirme

1.2. Fizik tedavi

1.3. Farmakolojik tedavi

1.4. Psikiyatrik destek tedavisi

1.5. Oklüzal splint tedavisi

2. Geri Dönüşümsüz Tedavi

2.1.Oklüzal uyumlama

2.2.Cerrahi girişimler (artroskopi ve artrotomi)

3.Alternatif tedaviler

3.1.Botoks uygulamaları

3.2.Bruksizmin önlenmesinde tat almaya dayalı yaklaşım (Biofeedback)

\section{3..Hipnoz kullanımı}

\subsection{Vakum önleyici}

\section{Geri Dönüşümlü (Koruyucu) Tedavi: 1.1.Bilgilendirme}

Öncelikle hasta parafonksiyonel alışkanlığından haberdar edilmeli, bilgilendirilmeli ve gün içinde bir dereceye kadar kontrol edilebileceği söylenmelidir. Bu amaçla hastaya dildamak egzersizleri yaptırılabilir. Semptomlarda potansiyel rol oynayan psişik faktörler kontrol edilmelidir. Bu amaçla gerekiyorsa psikoterapi uygulanabilir ya da yoga gibi rahatlatıcı yöntemler denenebilir $[15,16]$.

\subsection{Fiziktedavi}

Transkutanöz elektriksel sinir uyarımı (TENS), ultrason, masaj, soğuk ve sıcak uygulamaları, enjeksiyon ve egzersiz gibi metotlardır. Böylece hastanın ağrısı azalır, kasılmış bulunan kaslar gevşer, kısalmış dokuların gerilmesi için ortam oluşur[14].

\subsection{Psikiyatrik Destek Tedavisi}

Bruksizm sıklıkla anksiyete ile ilişkili olmaktadır. Stresten uzaklaşabilmek için psikoterapötik yaklaşımlara ihtiyaç duyulmaktadır. Hasta danışmanlığı, bruksizmin şiddetinin azalmasını ve aynı zamanda alışkanlığın farkına varıımasını sağlar. Bu, hastanın kendini kontrolünde artışa sebep olur ve böylece parafonksiyonel diş hareketleri azalabilir [16].

\subsection{Farmakolojik Tedaviler}

Benzodiazepinler, santral kas gevşeticiler ve trisiklik antidepresanlar orofasial ağrı yönetiminde ve UB tedavisinde kullanılan ilaçların bazılarıdır. Dopamin agonistleri, propranolol ve botulinum toxin A gibi diğer ilaçlarsa bu amaçla nadiren kullanılırlar. İlaçların spesifik etkisi, yeterliliği ve güvenilirliliği üzerine yapılmış az sayıda kontrollü çalışma vardır [17].

\subsection{Okluzal Splintler}

Geri dönüşümlü tedavi seçeneklerinden biri olan oklüzal splintler TME'nin fonksiyonunu arttırmak ve stabilize etmek, çiğneme sistemi fonksiyonlarını geliştirmek, anormal kas aktivitelerini azaltmak, dişleri atrizyondan ve travmatik kuvvetlerden korumak amacıyla alt ve üst çeneye uygulanan genellikle akrilik yapıdaki apareylerdir [18].

Oklüzal Splintlerin Amaçlarl;

1. Erken veya yanlış temasları elimine etmek

1. Kaslarda gevşeme sağlamak

2. Dişleri aşınmaya karşı korumak

4. Eklemdeki aşırı yüklenmeyi hafifletmek

5. Kondilleri fizyolojik pozisyona getirmek

6. Hastaların yeni bir oklüzyon veya dikey boyuta cevabını kontrol etmektir.

Splintlerin etkili olmaları bir çok mekanizmanın kombinasyonuyla ortaya çıkar. Bu mekanizmalar şu şekilde açıklanabilir: [14]

1.Oklüzal durumun değişmesi: Oklüzal splint kullanımıyla daha stabil ve optimum bir durum sağlanır. Böylece kas aktivitesi ve semptomlar geriler [19].

1. Kondiler durumun değişmesi: Kondil, ya muskuloskeletal olarak en stabil olan pozisyonda ya da doku bütünlüğünün ve fonksiyonun daha rahat sağlanabildiği pozisyonda tespit edilir.

2.Dikey boyutun artması: Dikey boyuttaki artış miktarının kas aktivitesini ve semptomları gerilettiği bildirilmiştir.

4. Zihinsel farkındalığın gelişmesi: Kullanan hasta fonksiyonel ve parafonksiyonel davranışlarının farkına varır.

5.Plasebo etkisi: Oklüzyonsuz (plasebo) bir aparey kullanıldığı durumlarda, dahil edildikleri araştırmada plasebo kullanıldığını bilen hastalarda, plasebo apareylerle iyileşme 1/2 oranındayken; plasebo kullanıldığını bilmeyen hastalarda iyileşme, 1/2 ten daha fazladır. Buna Hawthorne etkisi denir [15].

Laskin'e göre klinik uygulamalarda kullanılan oklüzal splint tipleri: [22]

1. Stabilizasyon splintleri

1. Ön ısırma plağı ve arka ısırma plağı

2. Ön konumlandırma splinti

4. Yumuşak splintlerdir. 


\section{Stabilizasyon splintleri}

Tüm arkı kaplayan stabilizasyon splintleri; Michigan splinti, Fox apareyi, Tanner apareyi, düz yüzeyli splint, gece plağı ve Ramfjord apareyi olarak da bilinir [20]. Bu splint tipi statik olarak sentrik ilişkide oluşan sentrik oklüzyonu sağlar ve dinamik olarak da ön diş rehberliği sağlar. Genellikle daha fazla dişin eksik olduğu çeneye yapılır, ancak bu hastanın iskeletsel ve dişsel ark formuna bağlıdır. Tüm gün splint kullanan hastaların üste yapılan apareyi daha kolay tolore ettikleri görülmüştür. Stabilizasyon splinti ağrı ve disfonksiyonunun olduğu TMR'de kullanılabilir [21].

\section{Ön Isırma plağı}

Ön ısırma plağı, üst dişleri kaplayan ve sadece mandibular ön dişlerle temas sağlayan bir apareydir. İdeal bir ön rehberlik sağlayarak ve azı dişlerini temastan çıkararak aşırı kasılmış çiğneme kaslarını rahatlatabilir [22]. Ön ısırma plağı, kas disfonksiyonlarının başlangıç tedavisinde ortalama 3-6 gün kullanılabilir [19]. Uzun süre kullanımında karşıt dişle teması olmayan arka dişlerin supraerüpsiyonu görülebilir, bu da açık kapanışa yol açabilir.

\section{Ön konumlandırma splinti}

Bu splint, çeneyi tamamen örten ve alt çeneyi interküspal pozisyondan daha öne ve aşağı yönlendirerek konumlandıran bir apareydir. Bu pozisyon hasta ağzını açıp kapattığında tıklamanın olmadığı pozisyondur. Böylelikle retrodiskal dokulara, adapte olmaları veya iyileşmeleri için izin verilir Bazı araştırmacılar tüm gün hatta yemek yerken bile kullanılmasını ve yaklaşık 6-7 hafta bu şekilde kullanımı önerirken bazıları da sadece gece yatarken ve 2-6 ay kullanımı önermektedir [19,20].

\section{Yumuşak splintler}

Yumuşak splintler termoplastik malzemeden yapılan apareylerdir. Belirli bir kalınlıktadır ve karşı dişlerle ilişkisini dengelemeye ve ayarlamaya gerek yoktur. Karşıt dişlerle devamlı temas sağlanır. Bu splint ağrı ve disfonksiyonu olan hastalarda acil müdahale için kullanılır. Wright, yumuşak splint kullananlarda oklüzal değişikliklerin oluştuğunu belirtmiştir. Uyumlandırımışyumuşak splint kullanımının oklüzal değişikliğe neden olmadığı; uyumlandırılmayan apareylerde hastaların semptomlarında artış olduğu bildirmiştir [23]. Ayrıca yumuşak splintlerin parafonksiyonel aktiviteyi tetikleyeceğini belirtmiştir

\section{Geri Dönüşümsüz Tedavi}

\subsection{Okluzal Uyumlama}

Yalnızca bruksizmin erken aşamalarında kullanılmalıdır. Oklüzal çatışmaların elimine edilmesi amacıyla selektif mölleme ya da kesim teknikleri kullanılarak uygulanır. Oklüzal uyumlama proflaktik bir yöntemdir. Herhangi bir erken temas varlığı varsa, koronoplasti (diş yüzeyi düzeltmeleri) ile düzeltilmelidir. Oklüzal bir ayarlama yapmadan önce, çenenin normal fizyolojik hareketlerine devam etmesi için kasların rahat ve normal pozisyonlarının korunması gerektiği bilinmelidir [24].

\subsection{Cerrahi Girişimler}

Eklemi oluşturan kemik ve kıkırdak dokulara uygulanan cerrahi işlemlerden oluşmaktadır. Sıklıkla eklem içi basıncı azaltan sıvı çıkışını sağlayarak veya eklem içi kayganlığı arttırıcı sıvı takviyesiyle olur [24].

\section{Alternatif Tedaviler}

\subsection{Botoks Uygulamaları}

Botulinum toksin (Botoks), Clostridium Botulinum'dan üretilen bir ekzotoksindir. Bu toksin kolinerjik sinir motor son plaklarında asetilkolin salınımını bloke ederek, kaslarda ve bezlerde geçici inaktivasyona sebep olur. Bruksizm tedavisinde botoks uygulamaları genellikle masseter kasa yapılırken masseter ve temporal kasın sinerjik etkisini göz önünde bulunduran çalışmalarda her iki kasa da enjeksiyon yapılmıştır. Ancak bu iki uygulama arasında ki farkları gösteren yeterli sayıda çalışma bulunmamaktadır.Son yıllarda gündüz ve uyku bruksizminin tedavisinde botoks kullanımı tartışılmaktadır. Botulinum toksinin bruksizm semptomlarını azalttığı kanıtlanmıştır [25].

Botoks, istemsiz orofasiyal hareketler ve hareket bozukluklarına bağlı sekonder gelişen bruksizmi tedavi etmede de kullanılabilir. Ancak, uyku bruksizmi üzerindeki etkileri halen objektif ölçümler ile tam olarak değerlendirilememiştir. Bazı çalışmalar yalnızca uyku bruksizmi olan bireylerde botoks enjeksiyonu yapıldığında çenenin motor hareketlerinin sıklığında ve bruksizme bağlı olan ağrı seviyesinde azalma olduğunu göstermiştir. Ayrıca ağrının azalmasında oral splint uygulaması ile botoks uygulamasının istatistiksel olarak eşit seviyede etkili olduğu gösterilmiştir. Bu çalışmalar subjektif değerlendirilmiş, EMG veya polisomnografi gibi objektif değerlendirme yöntemleri ile desteklenmemiştir [25,26].

\subsection{Bruksizmin Önlenmesinde Tat Almaya Dayalı Yaklaşım (Biofeedback)}

Bruksizm tedavisinde tada dayalı biyofeedbackmekanizmasının kullanılması yeni ve radikal bir yöntemdir. Yöntemde; çok hoşlanılmayan, güvenilir sıvılar (örn. deniz suyu) küçük plastik kapsüller içine yerleştirilir. Üst ve alt dişler arasında konumlandırılan, özel olarak tasarlanmış dental apareylere sağ ve sol tarafta birer kapsül bağlanır. Aparey ve kapsüller geceleri 
ya da bruksizmin gerçekleştiği zamanlarda kullanılır. Hasta kuvvetle ısırmaya başladığında kapsüller yırtılarak likit ağza akar. Likit hastanın bilinçli olarak dikkatini çeker ve diş sıkma ya da gıcırdatma olayını önler. Bu metodun varyasyonları ve kullanılan aparey bruksizm teşhisi amacıyla da kullanılabilir. Ayrıca bu yöntem uzun dönem kullanıldığında bir kronik bruksizm vakasında başarılı sonuçlar sergilemiştir [27].

\subsection{Hipnoz Kullanımı}

Yıllarca diş hekimleri bruksizm ve temporomandibular eklem bozukluklarıyla başa çıkmakta zorlanmışlardır. Genellikle, bruksizm ile başa çıkabilmek için bireysel sorunları ve kişinin bilinçaltında yatan nedenleri ortadan kaldırmak gerekmektedir. Diş sıkma basit bir alışkanlık olarak meydana gelir ve uzun dönemli duygusal sorunlar problemi gittikçe büyütebilir. Hastanın bu sorunlarını hafifletebilmek için sıklıkla kullanılan yöntem, ona kendi kendini rahatlatmanın basit bir prosedürünü öğretmektir. Hipnoz ile kişinin kendini kontrol etmesi ve rahatlatması sağlanabilir [28].

\subsection{Vakum Önleyici}

Vakum önleyici Long'a göre dişlerin uzun süre gıcırdatılması için intraoral bir vakumun oluşturulup sürdürebilmesi gereklidir [29]. Bu vakumun oluşumunun önlenmesi amacıyla paslanmaz çelik telden basit bir uygulama yapılır. Buna ilaveten iki plastik kamış uyumlanarak basıncın önlenmesi amacıyla iki plastik delikli pul ile birlikte ters döndürülüp yerleştirilir. Bu uygulama uzun süredir devam eden diş gıcırdatma olayının önlenmesi amacıyla kullanılabilir. Diş gıcırdatmayı azaltarak yalnızca kısa süreli nöbetler halindeki bruksizm seyrini değiştirebilir, total bruksizm miktarı aynı kalır [30].

\section{Çıkar çatışması / finansal destek beyanı}

Bu yazıdaki hiçbir yazarın herhangi bir çıkar çatışması yoktur. Yazının herhangi bir finansal desteği yoktur

\section{Kaynakça}

1. Shetty S, Pitti V, Satish Babu CL, Surendra Kumar GP, Deepthi BC. Bruxism: a literature review. J Indian Prosthodont Soc 2011; 10 $141-48$.

2. Manfredini D, Winocur E, GuardaNardini L, Paesani D, Lobbezoo F. Epidemiology of bruxism in adults: a systematic review of the literature. J Orofac Pain 2013; 27: 99-110.

3. Carlsson GE, Egermark I, Magnusson T. Predictors of Bruxism, Other Oral Parafunctions, and Tooth Wear over a 20-year follow up period. J Orofac Pain 2003; 17: 50-7.
4. Guo $H$, Wang $T$, Niu $X$ et al. The risk factors related to bruxism in children: A systematic review and meta-analysis. Arch Oral Biol 2018; 86: 18-34.

5. okubauskas L, Baltrušaitytè A, Pileičikienè G. Oral appliances for managing sleep bruxism in adults: a systematic review from 2007 to 2017. J Oral Rehabil 2018; 45: 81-95.

6. Grobet P, Gilon Y, Bruwier A, Nizet JL. [Sleep bruxism: state of the art and management]. Rev Med Liege 2017; 72: 410-15.

7. Mc Neill C. Management of temporomandibular disorders: concepts and controversies. J Prosthet Dent 1997; 77: 510-22.

8. Lobbezoo F, Jacobs R, De Laat A, Aarab G, Wetselaar P, Manfredini D. Chewing on bruxism. Diagnosis, imaging, epidemiology and aetiology. Ned Tijdschr Tandheelkd 2017;124:309-316.

9. Reddy SV, Kumar MP, Sravanthi D, Mohsin AH, Anuhya V. Bruxism: a literature review. J Int Oral Health 2014;6:105-9.

10. Klasser GD, Rei N, Lavigne GJ. Sleep bruxism etiology: the evolution of a changing paradigm. J Can Dent Assoc 2015; 81: 2.

11. Darien IL. Sleep related bruxism. In International Classification of Sleep Disorders. 3rd ed. Chicago: American Academy of Sleep Medicine; 2014.

12. Lavigne GJ, Manzini C, Kato T. Sleep bruxism. In Principles and Practice of Sleep Medicine. 6th ed. Philadelphia: Elsevier; 2005.

13. Miloro M, Ghali GF, Larsen P, Waite P. Peterson's Principles of Oral and Maxillofacial Surgery. 2nd ed. Hamilton: B.C. Decker Inc; 2004.

14. Okeson JP. Management of Temporomandibular Disorders and Occlusion. 3rd ed. Florida, USA: Mosby; 1992.

15. Johansson A, Omar R, Carlsson GE. Bruxism and prosthetic treatment: a critical review. J Prosthodont Res 2011; 55: 127-36.

16. De Leeuw $\mathrm{R}$, ed. Orofacial pain. Guidelines for assessment, diagnosis, and management. 4th ed. Chicago, IL: Quintessence Publishing Co, Inc., 2008.

17. Wahlund $\mathrm{K}$, List $\mathrm{T}$, Larsson $\mathrm{B}$, Treatment of temporomandibular disorders among adolescents: A comparison between occlusal appliance, relaxation trainig, and brief information. Acta Odontol Scand 2003; 61: 203-11.

18. De Boover JA, Van Der Berge L, De Boever AL, Keersmakers K. Comparasion of clinical profiles and treatment outcomes of an elderly and a younger temporamandibular patient group, J Proshet Dent 1999; 81: 312-17.

19. Mc Neill C. Temporomandibular Disorders: Guidelines for Classification, Assessment, and Management. 1st ed. San Francisco: Quintessence Publishing Co; 1993. 
20. M. Kreiner, Edwin Betancor, Glenn T. Clark, Occlusal stabilization appliances: Evidence of their efficacy. J Am Dent Assoc. 2001; 132: 770-77.

21. Yap AU. Effects of stabilization appliances on nocturnal parafunctional activites in patients with and without signs of temporomandibular disorders. J Oral Rehabil 1998; 25: 64-68.

22. Laskin DM, Greene CS, Hylander WL. Clinical Management. An evidence based approach to diagnosis and treatment, 1. ed, Texas, Quintessence Publishing Co. 2006.

23. Egermark I, Carlsson GE, Magnusson T. A 20-year longitudinal study of subjective symptoms of temporomandibular disorders from childhood to adulthood. Acta Odontol. Scand 2001; 59: 40-48.

24. Gray RJ, Davies SJ, Quayle AA. A Clinical Approach to Temporomandibular Disorders. 4. Examination of Articulatory System: Occlusion. Br Dent J 1994; 177: 63-68.

25. Gu W, Yang J, Zhang F, Yin X, Wei X, Wang C. Efficacy of biofeedback therapy via a mini wireless device on sleep bruxism contrasted with occlusal splint: a pilot study. J Biomed Res 2015; 29: 160-68.
26. GuardaNardini L, Manfredini D, Salamone M, Salmaso L, Tonello S, Ferronato G. Efficacy of botulinum toxin in treating myofascial pain in bruxers: a controlled placebo pilot study. Cranio 2008; 26: 126-35.

27. Nissani M.Can taste aversion prevent bruxism Appl Psychophysiol Biofeedback 2000; 25: 43-54.

28. Somer E. Hypnotherapy in the treatment of the chronic nocturnal use of a dental splint prescribed for bruxism. Int J Clin Exp Hypn 1991; 139: 145-54.

29. Long JH. Jr. A device to prevent jaw clenching. J Prosthet Dent 1998; 79: 353-4.

30. Pintado MR, Anderson GC, Long R, Douglas WH. Variation in tooth wear in young adults over a two-year period. J Prosthet Dent. 1997; 77: 313-320. 